\title{
Optimal Approaches to Skin Preparation Prior to Neurosurgery
}

\author{
Erin KM Graves, ${ }^{1}$ Lauren E Stone, ${ }^{1,2}$ and Christopher M Loftus ${ }^{1}$ \\ 1. Department of Neurological Surgery, Temple University School of Medicine, Philadelphia, PA, USA; 2. Department of Neurological Surgery, \\ St. Luke's University Health Network, Bethlehem, PA, USA
}

DOI: https://doi.org/10.17925/USN.2020.16.1.50

S urgical site infections (SSIS) are serious operative complications that carry marked costs for both patients and the healthcare system. In neurosurgical procedures, infection in close proximity to the central nervous system can result in longer hospital stays, readmissions, prolonged recovery, and patient mortality. While risk factors for SSIs have been assessed in the literature, the development of effective skin preparation remains a topic of interest in the effort to reduce SSI incidence. In this review, we discuss the current conversation in neurosurgical SSI development and the skin preparation interventions best supported to reduce SSI occurrence.

\section{Keywords}

Surgical site infection, neurosurgery, anti-bacterial agent, infection control

Disclosures: Erin KM Graves, Lauren E Stone, and Christopher M Loftus have no financial or non-financial relationships or activities relating to this article.

Review Process: Double-blind peer review.

Compliance with Ethics: This article involves a review of the literature and did not involve any studies with human or animal subjects performed by any of the authors.

Authorship: The named authors meet the International Committee of Medical Journal Editors (ICMJE) criteria for authorship of this manuscript, take responsibility for the integrity of the work as a whole, and have given final approval for the version to be published.

Access: This article is freely accessible at touchNEUROLOGY.com (c) Touch Medical Media 2020

Received: March 1, 2019

Accepted: February 14, 2020

Published Online: July 10, 2020

Citation: US Neurology. 2020:16(1):50-3

Corresponding Author: Christopher M Loftus, Department of Neurosurgery, 3401 North Broad Street, Suite C540, Philadelphia, PA 19140, USA.

E:cmloftus@icloud.com

Support: No funding was received for the publication of this article.
Infections and their prevention have long been a significant concern for surgeons around the world. Surgical site infections (SSIS) represent a considerable burden for both patients and providers alike, as they often result in significant morbidity and mortality, as well as high costs to healthcare systems. In the United States, SSIs have been identified as one of the most common healthcare-associated infections, constituting $>20 \%$ of such infections, ${ }^{1}$ and they cost acute care hospitals more than $\$ 3$ billion annually. ${ }^{2}$ The majority of these infections are attributable to skin flora, in particular Staphylococcus spp., such as S. aureus, and coagulase-negative staphylococci. ${ }^{3,4}$ The prevalence of specific organisms, however, varies with the type of procedure and patient comorbidities. As many as half of all SSIs are likely preventable with the implementation of evidence-based interventions. ${ }^{5}$

Neurosurgeons are certainly not strangers to the SSI, and such infections in neurosurgical patients represent a particularly serious hazard given their proximity to, or location within, the central nervous system. Complications in post-operative neurosurgical patients include skin and soft-tissue infections, calvarial or vertebral osteomyelitis, meningitis, subdural empyema, spinal epidural and cerebral abscesses, and infections requiring the removal of implanted hardware or devices. ${ }^{6,7}$ These complications often result in reoperation, longer hospital stays, and prolonged rehabilitation. Plotting the trends in neurosurgical SSIs has proven to be challenging due to procedural and patient diversity. Some studies suggest that neurosurgical SSI rates are higher than the overall average of $2 \%$ of all surgical procedures. ${ }^{8,9}$ One series of 949 neurosurgical patients, for example, found an overall incidence of $4.5 \%{ }^{8}$

Risk factor analyses underscore the challenge of broadly sorting SSI contributors across neurosurgical subspecialties. Several studies have focused on patient characteristics and comorbidities as risk factors for SSI development. In spine surgery, for example, glycemic control, smoking, and obesity have been identified in multiple series as risk factors. 10,11 Studies of post-cranial surgery patients, however, highlight factors, such as previous irradiation, post-operative drain placement, history of previous procedures, extended stay in the intensive care unit, cerebrospinal fluid leak, American Society of Anesthesiologist's score, number of individuals present in the operating room, and extended operative time., ${ }^{6,12-14}$ Interestingly, each of these factors was of varying significance in the various cranial surgery subtypes (i.e., pediatric, functional, etc.), which contributes to the challenge of better understanding infection control in the neurosurgical operating theater.

Due to the significant impact of SSIs on patient care and the healthcare system, attention to provider-dependent interventions for SSI reduction is critical. Several studies have identified effective interventions for SSI prevention, including close attention to skin preparation. ${ }^{5,15}$ In respect to these findings, this review explores the currently available options for skin preparation prior to neurosurgery and evaluates their effectiveness in reducing SSIs. 
Table 1: Microbial coverage of available skin preparation agents

\begin{tabular}{|c|c|c|c|c|}
\hline & Aqueous iodophors 16,20 & $\mathrm{CHG}^{17,20}$ & Alcoholic iodophors ${ }^{18,20}$ & CHG-alcohol ${ }^{18,20}$ \\
\hline Gram+ bacteria & Excellent & Excellent & Excellent & Excellent \\
\hline Gram-bacteria & Good & Good & Improved & Improved \\
\hline Mycobacteria & Good & Poor & Improved & Improved \\
\hline Fungi & Good & Fair & Good & Improved \\
\hline Viruses & Good & Good & Good & Good \\
\hline
\end{tabular}

$\mathrm{CHG}=$ chlorhexidine gluconate.

Table 2: Mechanisms of action and usage recommendations for available skin preparation agents

\begin{tabular}{|c|c|c|c|c|}
\hline & Aqueous iodophors ${ }^{16,20}$ & $\mathrm{CHG}^{17,20}$ & Alcoholic iodophors ${ }^{18,20}$ & CHG-alcohol 18,20 \\
\hline Mechanism of action & Oxidation/substitution with free iodine & Disrupts cell membrane & (See components) & (See components) \\
\hline Rapidity of action & $\uparrow$ & $\uparrow$ & $\uparrow \uparrow$ & $\uparrow \uparrow$ \\
\hline Safe for use on eyes ${ }^{19}$ & $5 \%$ ophthalmic solution & No & No & No \\
\hline Safe for use on ears ${ }^{19}$ & Yes & No & No & No \\
\hline Other precautions ${ }^{19}$ & $\begin{array}{l}\text { Caution in burn patients, } \\
\text { thyroid disorders, neonates, pregnant } \\
\text { and lactating women }\end{array}$ & $\begin{array}{l}\text { Caution in premature infants } \\
\text { or those }<2 \text { months old }\end{array}$ & $\begin{array}{l}\text { Flammable. Do not use for } \\
\text { infants }<2 \text { months old. } \\
\text { Caution for lactating women }\end{array}$ & $\begin{array}{l}\text { Flammable. Caution in premature infants } \\
\text { or those }<2 \text { months old }\end{array}$ \\
\hline
\end{tabular}

CHG $=$ chlorhexidine gluconate.

\section{Current options for pre-surgical skin preparation}

A variety of antiseptic agents are available for preparing skin prior to surgery. Options include alcohol (ethyl alcohol 60-90\% or propyl alcohol 50-91\%), chlorhexidine (with or without alcohol), iodophors (with or without alcohol) and para-chloro-meta-xylenol and triclosan (used in surgical scrubs). An overview of the current recommended practices and the most frequently used skin preparation materials are presented in Tables 1 and $2^{16-21}$ and detailed in the following sections. It is important to remember that the performance of the currently available surgical antiseptics is variable. For example, aqueous iodophors, such as povidone-iodine (Betadine ${ }^{\circledast}$, Avrio Health L.P., Stamford, CT, USA), for scrubs/paint application are immediate onset and last approximately 2 hours. Alcohol-iodophors (e.g. DuraPrep ${ }^{\mathrm{TM}}$, 3M, Saint Paul, MN, USA) have a similar rapid onset and last significantly longer (48-96 hours). A similar contrast is seen with alcohol and chlorhexidine gluconate (CHG) solutions, which convey a 48-hour duration of activity compared with just 6 hours for aqueous CHG solutions (e.g. Hibiclens ${ }^{\circledast}$, Mölnlycke Health Care, Norcross, GA, USA). ${ }^{20}$

Other important adjuncts to direct skin preparation include antibiotic-impregnated drapes, the use of preoperative antibiotic therapy and, of course, good sterile technique. The use of antibiotic-impregnated drapes has increased in recent years. In early studies, such drapes were shown to decrease overall bacterial count (iodine-impregnated drape versus paint alone, or paint with non-impregnated drape). ${ }^{22}$ However, a recent Cochrane review found no change in SSI incidence with iodineimpregnated drapes, although the use of no drapes is associated with increased infection incidence (risk ratio 1.23 ). ${ }^{23}$ Perioperative antibiotic therapies and good sterile technique have long been recognized in the literature as helpful in reducing the risk of SSI. 4,5,15,24

\section{Comparison between iodine and chlorhexidine-based compounds}

Both iodine and chlorhexidine-based preparations are widely used due to their broad-spectrum antimicrobial action as well as their efficacy and safety on nearly all skin surfaces. ${ }^{4}$ Iodine works by destroying microbial proteins and DNA, but requires combination with a solvent for administration. Several options are available, including aqueous and alcohol-based formulations. Alcohol-based solutions, such as iodine povacrylex in isopropyl alcohol, may have greater efficacy, easier application, improved durability and a superior cost profile. ${ }^{25}$ Furthermore, these alcohol-based solutions enhance adhesion between the prepared skin surface and the surgical drapes, theoretically limiting the spread of organisms onto the surgical field. However, if not allowed to dry completely or applied in areas with excessive body hair, flammability is a serious concern. ${ }^{20,26}$ Also of note, iodophors are inactivated by blood and serum proteins (whereas CHG is not), though their bacteriostatic effect continues while they remain on the skin and the clinical significance of this difference is not clear. ${ }^{4}$

Chlorhexidine is also a widely used preparation, works by disrupting bacterial cell membranes, and is most commonly produced as $\mathrm{CHG}$ in either an aqueous or alcohol-based solution. ${ }^{4}$ In a prospective randomized trial of 500 surgical patients, chlorhexidine was found to significantly reduce rates of bacterial colonization and SSI incidence versus povidone-iodine. 
Bacterial colonization was measured via cultures taken at the time of operation and resultant infection rates were recorded. ${ }^{20} \mathrm{~A}$ similar multi-hospital study further supported these results: Paocharoen et al. randomized nearly 900 adults undergoing clean-contaminated surgery to either a CHG-alcohol prep or an iodophor-alcohol prep and demonstrated a significantly lower incidence of SSI within 30 days of surgery in the $\mathrm{CHG}$-alcohol group (9.5\% versus $16.0 \%$ in the iodophor-alcohol group). ${ }^{27}$

More recent studies, however, complicate these results. One notable study of over 3,000 general surgery patients performed by Swenson et al. at a single center randomized patients to three skin preparation groups: povidone-iodine scrub-paint combination, 2\% CHG and 70\% isopropyl alcohol (ChloraPrep ${ }^{\mathrm{TM}}$, Becton, Dickinson and Company, Franklin Lakes, NJ, USA), or iodine povacrylex in isopropyl alcohol (DuraPrep ${ }^{\mathrm{TM}}$ ). Infection rates for each group were $6.4 \%, 7.1 \%$, and 3.9\%, respectively, suggesting that iodophor-based preps may be superior to $\mathrm{CHG}$ preps in the general surgery population. ${ }^{28}$ However, the Liu et al. 2018 overview of 73,053 patients represented in 30 cochrane reviews found no clear difference in SSI incidence as a complication of preparation choice. ${ }^{29}$

\section{Special challenges for neurosurgical procedures- neurotoxicity}

The questionable neurotoxicity of skin-preparation solutions presents a challenge unique to neurosurgical procedures. Despite having superior antiseptic properties to iodophor solutions, CHG is considered, by some, to be inappropriate for neurosurgery as in vitro evidence has suggested neurotoxicity. ${ }^{30}$ Several studies from the 1970s further suggested that CHG may have the capacity to reduce hearing and taste post-operatively. ${ }^{31-33}$ Henshen and Olsen's 1984 animal model study seemed to corroborate this finding, with results suggesting that $\mathrm{CHG}$ can cause damage to ocular autonomic nerve fibers, evidenced for up to 50 days after exposure. ${ }^{34}$ For this reason, chlorhexidine solutions carry a warning against use "for lumbar punctures or... contact with the meninges," although a Mayo Clinic study of 11,095 patients receiving chlorhexidine preparation before spinal anesthesia revealed only a $0.04 \%$ incidence of neurologic complications. ${ }^{35}$

The role that the alcohol component in many skin-preparation solutions may have in neurotoxicity is also worth mentioning. Alcohol has established neurotoxic properties - in fact, this effect is employed therapeutically in some neurolysis procedures that use ethanol to lesion nerves. ${ }^{36,37}$ The existing literature regarding the role that the isopropyl alcohol component of $\mathrm{CHG}$ solutions may play in neurotoxicity is limited and primarily comes from the anesthesiology community regarding skin-preparation choice prior to neuraxial blockage. ${ }^{36}$ This literature suggests that the benefits of using these skin-preparation agents outweigh the potential risks, possibly due to the low volume of exposure. Unfortunately, there have been no studies looking at this specifically in the neurosurgical literature.

\section{Skin preparation technique}

Beyond choice of skin-preparation agent, the method for application should also be considered. Per the Centers for Disease Control and Prevention (CDC) Guidelines for the Prevention of Surgical Site Infection, the surgical site must be cleaned thoroughly prior to preparation. ${ }^{5}$ Specifically, any gross contaminants such as dirt or oil should be removed. The chosen antiseptic agent should then be applied in concentric circles, outward from the anticipated incision site. ${ }^{4}$ The management of hair at the surgical site is addressed in detail below, but this step would occur prior to the application of antiseptic.

\section{Special challenges for neurosurgical procedures-hair and hair removal}

Many, if not most, neurosurgical procedures contend with hair as a possible source of infection. Traditionally, significant shaving occurred preoperatively in order to reduce this risk, but the evidence supporting this practice is inconsistent. A systematic review by Broekman et al. reviewed preoperative shaving outcomes in 11,071 adult and pediatric neurosurgical patients from 21 different studies and concluded that this practice should not be standard-of-care due to lack of literature support. ${ }^{38}$ One randomized clinical trial in the study identified a statistically significant increased number of shaved pre-spinal surgery patients with postoperative infection versus those who were not shaved. ${ }^{39}$ Furthermore, hair removal has been addressed by a number of organizations, including the $\mathrm{CDC}$, which recommends against removing hair, although electric clippers or depilatory agents are permissible if necessary for access to the surgical site. ${ }^{40,41}$ If hair is to be removed, it should be done immediately before the operation. ${ }^{4}$ Furthermore, the use of alcohol-based preparations has also been discouraged in hairy areas by the US Food and Drug Administration because of the flammability risk. If such solutions must be used, it is recommended that 1 hour be allotted to allow solutions to dry. ${ }^{20}$

\section{Current practices and future developments for neurosurgical skin preparation}

Unfortunately, no clear guidelines currently exist for choice of skin preparation in neurosurgery. Some institutions have developed their own practice guidelines based on literature reviews, but the choice of skin preparations largely remains a function of the individual neurosurgeon's preference and what preparation solutions are available at a given institution.

As greater attention is turned to the effects of various skin preparations in neurosurgery, we expect to see several developments occur. While it is unlikely that alcohol will be eliminated from the iodoform-based preparations, the authors believe that more time will be given to allow these preparations to dry prior to the initiation of surgery to improve patient safety. The authors also anticipate that current guidelines from the broader surgical community literature will begin to emphasize these points for the neurosurgical subspecialty.

The authors expect to see a complete elimination of shaving and the extensive clipping of surgical sites, as traditional methods are abandoned and evidence from microbiological studies are accepted. In its place, there will likely be increased use of minimal clipping combined with antiseptic shampoos followed by an iodoform-based preparation at the surgical site. There is also likely to be an increased use of self-adhesive drapes containing iodine povacrylex (i.e., Ioban ${ }^{\mathrm{TM}}, 3 \mathrm{M}$, Saint Paul, MN, USA), although current recommendations do not regard this as necessary SSI prevention. ${ }^{5}$ In addition, the authors expect to see further impetus for rigorous, evidenced-based hospital protocols as SSI becomes prioritized as a national health concern. Indeed, some institutions have already documented significant SSI reduction with full-scale adoption of such protocols. ${ }^{15,41}$ 
These practices-the use of povidone/iodine-based preparations, use of appropriate surgical drapes, and the elimination of shaving and reduction of clipping-should begin to decrease the overall risk of SSIS in neurosurgical patients. The combination of these with the standard use of preoperative antibiotics and good sterile technique should make neurosurgery less prone to infection, thereby improving patient morbidity and outcomes, and reducing costs for the healthcare system as a whole. $]$
1. Magill SS, Edwards JR, Bamberg W, et al. Multistate point-prevalence survey of health care-associated infections N Eng J Med. 2014;370:1198-208.

2. Zimlichman E, Henderson $D$, Tamir $\mathrm{O}$, et al. Health care-associated infections: a meta-analysis of costs and financial impact on the US health care system. JAMA Intern Med. 2013;173:2039-46.

3. Korol $\mathrm{E}$, Johnston $\mathrm{K}$, Waser $\mathrm{N}$, et al. A systematic review of risk factors associated with surgical site infections among surgica patients. PLOS One. 2013:8:e83743.

4. Mangram A, Horan TC, Pearson ML, et al. Guidelines for prevention of surgical site infection, 1999. Am I Infect Control. 1999:27:97-134.

5. Berríos-Torres SI, Umscheid CA, Bratzler DW, et al. Centers for Disease Control and Prevention guideline for the prevention of surgical site infection, 2017. JAMA Surg. 2017;152:784-91.

6. Schipmann S, Akalin E, Doods J, et al. When the infection hits the wound: matched case-control study in a neurosurgical patient collective including systematic literature reviow and risk factors analysis. World Neurosurg. 2016:95:178-89.

7. Fang C, Zhu T, Zhang P, et al. Risk factors of neurosurgical site infection after craniotomy: a systematic review and meta-analysis. Am I Infect Control. 2017;45:e123-34.

8. Cassir N, De La Rosa S, Melot A, et al. Risk factors for surgical site infections after neurosurgery: a focus on the postoperative period. Am J Infect Control. 2015:43:1288-91.

9. Klevens RM, Edwards JR, Richards CL Jr, et al., Estimating health care-associated infections and deaths in US hospitals, 2002, Public Health Rep. 2007:122:160-6.

10. Meng F, Cao J, Meng X. Risk factors for surgical site infections following spinal surgery. J Clin Neurosci. 2015;22:1862-6.

11. Hikata T, Iwanami A, Hosogane N, et al. High preoperative hemoglobin A1C is a risk factor for surgical site infection after posterior thoracic and lumbar spinal instrumentation surgery. J Orthop Sci. 2014:19:223-28.

12. Tolleson C, Stroh J, Ehrenfeld J, et al. The factors involved in deep brain stimulation infection: a large case series. Stereotact Funct Neurosurg. 2014;92:227-33.

13. Shibahashi K, Hoda H, Takasu Y et al. Cranioplasty outcomes and analysis of the factors influencing surgical site infection: a retrospective review of more than 10 years of institutional experience. World Neurosurg. 2017:101:20-5.
14. Sherrod BA, Arynchyna AA, Johnston JM, et al. Risk factors for surgical site infection following nonshunt pediatric neurosurgery: a review of 9296 procedures from a national database and comparison with a single-center experience. J Neurosurg Pediatr. 2017:19:407-20

15. Anderson PA, Savage JW, Vaccaro AR, et al. Prevention of surgica site infection in spine surgery. Neurosurgery. 2017;80:\$114-23.

16. Zamora JL. Chemical and microbiologic characteristics and toxicity of povidone-iodine solutions. Am J Surg. 1986;151:400-6

17. Lim KS, Kam PCA. Chlorhexidine-pharmacology and clinical applications. Anaesth Intensive Care. 2008;36:502-12.

18. Reichman $D E$, Greenberg JA. Reducing surgical site infections: a review. Rev Obstet Gynecol. 2009;2:212-21.

19. DailyMed. US National Library of Medicine. Product labels for all agents. Available at: http://dailymed.nIm.nih.gov (accessed March 14, 2020).

20. Hemani ML, Lepor H. Skin preparation for the prevention of surgical site infection: which agent is best? Rev Urol. 2009:11:190-5

21. Association of Perioperative Registered Nurses (AORN). Guidelines for Perioperative Practice 2019, Guideline for Preoperative Patient Skin Antisepsis, Recommendation III. Available at: https://pdfs.semanticscholar.org/ab7e/ e4d1472be36334c24d506bb8eb19d1645366.pdf (accessed February 18, 2020).

22. Lewis DA, Leaper DJ, Speller DC. Prevention of bacteria colonization of wounds at operation: comparison of iodine-impregnated ('Ioban') drapes with conventional methods. J Hosp Infect. 1984;5:431-7.

23. Webster J, Alghamdi A. Use of plastic adhesive drapes during surgery for preventing surgical site infection. Cochrane Database Syst Rev. 2015;CD006353.

24. Barnes S. What's new in SSI prevention? Aorn J. 2015;101:P10-2.

25. Darouiche RO, Wall MJ Jr, Itani KM, et al. Chlorhexidine-alcohol versus povidone-iodine for surgical-site antisepsis. N Eng/ J Med. 2010:362:18-26

26. Batra S, Gupta R. Alcohol based surgical prep solution and the risk of fire in the operating room: a case report. Patient Saf Surg. 2008;2:10

27. Paocharoen V, Mingmalairak C, Apisarnthanarak A. Comparison of surgical wound infection after preoperative skin preparation with
$4 \%$ chlorhexidine and povidone iodine: a prospective randomized trial. J Med Assoc Thai. 2009:92:898-902.

28. Swenson BR, Hedrick TL, Metzger R et al. Effects of preoperative skin preparation on postoperative wound infection rates: a prospective study of 3 skin preparation protocols. Infect Contro Hosp Epidemiol. 2009;30:964-71.

29. Liu Z, Dumville JC, Norman G, et al. Intraoperative interventions for preventing surgical site infection: an overview of Cochrane Reviews. Cochrane Database Syst Rev. 2018;CD012653.

30. Milstone AM, Bamford P, Aucott SW, et al. Chlorhexidine inhibits L1 cell adhesion molecule-mediated neurite outgrowth in vitro Pediatr Res. 2014;75:8-13.

31. Grover R, Frank ME. Regional specificity of chlorhexidine effects on taste perception. Chem Senses. 2008;33:311-8.

32. Schaupp $\mathrm{H}$, Wohnaut $\mathrm{H}$. Disturbances of taste from oral disinfectants. HNO. 1978;26:335-41.

33. Bicknell PG. Sensorineural deafness following myringoplasty operations. J Laryngol Otol. 1971;85:957-61.

34. Henschen A, Olson L. Chlorhexidine-induced degeneration of adrenergic nerves. Acta Neuropathol. 1984;63:18-23.

35. Sviggum HP, Jacob AK, Arendt KW, et al. Neurologic complications after chlorhexidine antisepsis for spinal anesthesia. Reg Anesth Pain Med. 2012;37:139-44.

36. Campbell JP, Plaat F, Checketts MR, et al. Safety guidline: skin antisepsis for central neuraxial blockade. Anaesthesia. 2014;69:1279-86.

37. Le Daré B, Gicquel T Therapeutic applications of ethanol: a review. J Pharm Pharm Sci. 2019;22:525-35.

38. Broekman ML, van Beijnum J, Peul WC, Regli L. Neurosurgery and shaving: what's the evidence? J Neurosurg. 2011;115:670-8.

39. Celik SE, Kara A. Does shaving the incision site increase the infection rate after spinal surgery? Spine. 2007:32:1575-7.

40. Centers for Disease Control and Prevention. Top CDC recommendations to prevent healthcare-associated infections. Available at: www.cdc.gov/HAl/pdfs/hai/top-cdc-recs-factsheet pdf (accessed February 18, 2020).

41. Schaffzin J, Simon K, Connelly B. Standardizing preoperative preparation to reduce surgical site infections among pediatric neurosurgical patients. J Neurosurg Pediat. 2017;19:399-406. 